\title{
Research of the ecologo-climatical niche of Brunnera sibirica Stev.
}

\author{
Marina V. Olonova', Anna S. Vedernikova', Thomas Albtight ${ }^{2}$ \\ I Biological Institute of Tomsk State University, Lenin Av., 36, Tomsk, 634050, Russia \\ 2 University of Nevada, Reno, USA \\ Corresponding author: Anna S. Vedernikova (anutaved@mail.ru)
}

Academic editor: R. Yakovlev | Received 3 July 2020 | Accepted 19 August 2020 | Published 6 November 2020

http://zoobank.org/20AEOBB9-DC39-43DB-ABB8-2A5F2F871A17

Citation: Olonova MV, Vedernikova AS, Albtight T (2020) Research of the ecologo-climatical niche of Brunnera sibirica Stev. Acta Biologica Sibirica 6: 413-421. https://doi.org/10.3897/abs.6.e56144

\begin{abstract}
Brunnera sibirica is a Southern-Siberian endemic herb. Being a Pliocene relict, it is included in Red Data Books of many Siberian regions. The aim of our study was to identify the climatic niche and territories suitable for this vulnerable species using the MaxEnt method. The climatic profile of B. sibirica was constructed using the BIOCLIM method with 19 bioclimatic variables. The research has revealed that the climatic conditions in the most of Siberian territory are not suitable for the growth of $B$. sibirica, which confirms its relic origin in the south of Siberia.
\end{abstract}

\section{Keywords}

Conservation, distribution, MaxEnt, Siberia, relict, areal, biodiversity

\section{Introduction}

Global biodiversity is known to be highly endangered. It suffers severely from destruction of natural ecosystems, caused by human activity. Due to deforestation, habitat change, over-exploitation, indiscriminate use of pesticides and other human impacts, we are now experiencing the rapid extinction (Meffe, Carroll 1994). The current rate of extinction is estimated to be over 1,000 times greater than the natural rate of extinction (Hijmans et al. 2012). Thus, the challenge of saving of biodiversity is a global problem of great importance. Relict plants with restricted distributions

Copyright Marina V. Olonova et al. This is an open access article distributed under the terms of the Creative Commons Attribution License (CC BY 4.0), which permits unrestricted use, distribution, and reproduction in any medium, provided the original author and source are credited. 
are the most sensitive and vulnerable and could be among the first to be extinct under adverse conditions. Therefore, the relict plants need a special protection.

The success of conservation activity largely depends on the knowledge of ecological and climatic needs of endangered plants. The identification of ecological niche, a correct and objective assessment of the most important environmental factors, as well as the determination of species ecological status are extremely important in plant conservation.

The application of GIS technologies into environmental studies gave a new powerful impetus for the development of this research. These methods, initially focused on purely practical needs of geodesists, geographers and geologists, now gain wide application in plant ecology and are rapidly developing (Franklin 2009; Scheldeman and van Zonneveld 2010).

Brunnera sibirica is a Southern-Siberian endemic. Its range is mainly restricted with chern dark coniferous forests of Altai and Western Sayan. It also was found in Tomsk and Novosibirsk provinces, and included in Red Data Books of the Altai Republic (1996), Tyva Republic (1999), Krasnoyarsk Krai (2012) Altai Krai (2006), Novosibirsk (1996), Kemerovo (2012), and Tomsk (2013) provinces. Such distribution and confinement to the relict area of Siberian broad-leaved forests and the chern dark coniferous forests ("black taiga"), which is a derivative of the now extinct Tertiary coniferous-broadleaf forests (Kleopov 1941; Epova 1956; Polozhiy and Krapivkina 1985) suggests the classification of this species in Siberia as a nemoral Pliocene relic (Polozhiy and Krapivkina 1985; Krapivkina 2009). Brunnera sibirica is a well-known and popular ornamental plant, and, in spite of being relict, it grows successfully not only in Western Siberia, but also in European Russia (Maevskiy 2006). Wintergoller (1983) suggested, that this species is extremely stable as it can remains in planted aeas without the slightest care for years, and occasionally can be found spontaneously in weedy places and in housing.

Genus Brunnera Steven. is presented with 3 species. Brunnera macrophylla (Adans.) I.M. Johnst. occurs in Caucasus, B. orientalis (Schensk.) I.M. Johnst. in Asia Minor, and B. sibirica Steven. in South Siberia (Dobrochaeva 1981). M.M. Ilyin (1941) suggested that this genus originated and formed in the ancient Mediterranean area.

The study of ecological and climatic features of rare, and especially relict species is of great theoretical and practical interest both for understanding their distribution and florogenesis in general (Popov 1958). As V.I. Chopik (1978) noted, relicts and endemics are some kind of accumulators of various biogeographic information. They can be used in the reconstruction of initial biogeographic conditions and serve as a key species for environmental forecasting.

\section{Material and methods}

To identify the locations of $B$. sibirica, the collections of ALTB, LE, MW, NS, NSK, TK and our collections and observations were used. Additional locations were taken from the Flora of Siberia (Nikiforova 1997). It is known that this species is being 
successfully cultivated in Eastern Europe, but in our studies we considered only natural locations. Our analysis involved 46 points located in Southern Siberia and some locations of natural plant communities in European part of Russia.

The climatic profile of B. sibirica was constructed using the BIOCLIM method. This method, developed by H. Nix (1986), is used to construct histograms of bioclimatic variables ${ }^{1}$ that reflect the climate profile of the species. The histogram, based on location data, shows the frequencies of different climatic parameters observed in analyzed area. "Climate envelope" allows visualizing a two-dimensional niche based on two selected climatic variables. The BIOCLIM method is implemented in the DIVA-GIS v. 7.5 software (Hijmans et al. 2012). Biologically significant climatic data - Bio1-Bio19 were obtained from the WORDCLIM database (Hijmans et al 2020). This data set is a grid with a spatial resolution of $2.5 \mathrm{arc}-\mathrm{min}$. The climatic characteristics, generated by interpolating the data from meteorological stations from 1950 to 2000 , are placed in nodes of this grid. The digital map, where the analysis results were projected, was constructed using ArcGIS 9.0 (ESRI 2012).

A potential range (suitable area), based on the species bioclimatic niche, was constructed using the MaxEnt method (Phillips et al 2006, 2020; Phillips and Dudic 2006). This method is currently considered to be one of the most effective presenceonly approaches, which do not require data on the species absence (Elith et al 2006; Giovanelli et al 2007; Scheldeman and van Zonneveld 2010). It shows the potential suitability of area for the species occurrence. The gradation of the tone from dark to light indicates the areas where this species can grow, or where it can spread in the future (Ward 2007). The method is also suitable for evaluating the contribution of each climatic variable to obtained species distribution model; therefore, we can analyze each biologically significant factor. In addition, we get valuable environmental information that characterizing the species (Scheldeman and van Zonneveld 2010).

In order to avoid the mistakes on interpreting how each input variable contributes to the model, the high correlated variables $(>0.7)$ were removed, using the algorithm of Brown (2014). Thus, only seven variables - Bio2, Bio7-Bio9, Bio15, Bio18, and Bio19 - were included in our analysis.

The contribution of each variable was evaluated in MaxEnt in two independent ways: by estimation of their contribution after permutation and using the jackknife option (Phillips et al 2006). The permutation approach detects the contribution of each variable. It is determined by randomly permuting the values of that variable among the training points (both presence and background) and measuring the re-

1 Bio1 - annual mean temperature, Bio2 - mean diurnal range ( $\max$ temp - min temp) (monthly average), Bio3 - isothermality (Bio1/Bio7) ${ }^{\star} 100$, Bio4 - temperature seasonality (coefficient of variation), Bio5 - max temperature of warmest period, Bio6 - min temperature of coldest period, Bio7 - temperature annual range (Bio5-Bio6), Bio8 - mean temperature of wettest quarter, Bio9 - mean temperature of driest quarter, Bio10 - mean temperature of warmest quarter, Bio11 - mean temperature of coldest quarter, Bio12 - annual precipitation, Bio13 - precipitation of wettest period, Bio14 - precipitation of driest period, Bio15 - precipitation seasonality (coefficient of variation), Bio16 - precipitation of wettest quarter, Bio17 - precipitation of driest quarter, Bio18 - precipitation of warmest quarter, Bio19 - precipitation of coldest quarter. 
sulting decrease in training AUC. A large decrease indicates that the model depends heavily on that variable (Ward 2007). The jackknife analysis indicated the training gain of each variable if the model was run in isolation, and compares it to the training gain with all the variables. This is useful to identify which variables contribute the most individually (Ward 2007). So, one of them shows how predictive each variable is individually and the other indicates how much model quality suffers if a single variable is removed from a multivariate MaxEnt model. To evaluate the model, we used a test sample that was $25 \%$ of all points of presence. Thus, 34 points were used for the training, and 11 points - for testing. The $10 \%$ threshold was set by default. This means that the climatic conditions of $10 \%$ of the presence points are supposed to be atypical habitats and their climatic characteristics were not taken into account when calculating the climatic niche (Scheldeman and van Zonneveld 2010).

While planning the conservation action, it is very important to predict the probable dynamics of ranges in accordance with various scenarios of climate change in the future. Following the initial model creation and analysis, we generated a model of potential distribution under climate change. We obtained gridded climatology based on 2080 Commonwealth Scientific and Industrial Research Organization (CSIRO), emission scenario - A2a. This scenario provides for a warming climate and an increase in the level of carbon dioxide in the atmosphere. We then projected a distribution model based on these these data and the relationships observed using MaxEnt.

\section{Results and discussion}

The study of herbarium materials and field data allowed clarifying the distribution of $B$. sibirica (Fig. 1). Having established a range of variability and frequency of different values of bioclimatic characteristics of Bio 1 - 19, the program BIOCLIM allowed thereby to establish the climatic niche of B. sibirica (Fig. 2). It is noticeable that distribution of temperature and precipitation indicators differs from normal and histograms show bimodality. It may be caused by current distribution of $B$. sibirica, which has formed a new enclave in European part of Russia (Maevskiy 2006). Then, the histograms, which concern the precipitation, especially Bio 13 (precipitation of wettest period), Bio 17 (precipitation of driest quarter), Bio 18 (precipitation of warmest quarter) and 19 (precipitation of coldest quarter) are asymmetric and turn out to be constrained from the left side. It may be caused by a number of points located in dry areas, where the precipitation of the wettest month does not exceed $82 \mathrm{~mm}$. In this case, the majority of the points fall in the range of $60-102.4 \mathrm{~mm}$, which corresponds to the first 2 bars of the histogram. Such a cut histogram may be caused by more sufficient influence of another factor, like temperature.

To assess the suitability of the territory of extratropical Eurasia for the growth of $B$. sibirica and possibilities of expanding its range, a model of probable distribution 


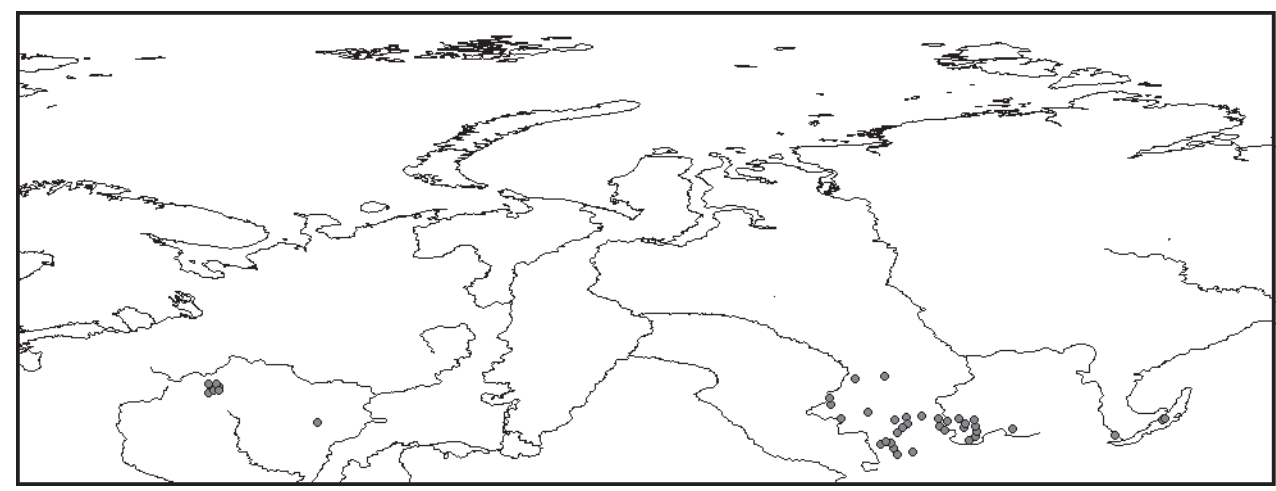

Figure I. Map of collecting Brunnera sibirica localities in Russia.

of $B$. sibirica was also constructed depending on bioclimatic factors. All 45 available points were used to create the distribution model, which mainly covered the entire distribution area of this species in Eurasia. Brunnera sibirica is known to be a vulnerable species nevertheless, it showed that the climatic conditions over a large area of South Siberia, the most of European part of Russia and even South Sakhalin and Japanese Hokkaido are quite suitable for this species (Fig. 3 A).

To evaluate the model, the AUC of the training and testing samples were calculated (both 0.97), the standard deviation was 0.007. Both obtained AUC values fall within the range of $0.9-1$, which corresponds to excellent discrimination (Scheldeman and van Zonneveld 2010).

Two complementary methods - permutation and jackknife - were used to evaluate the contribution of each used variable in the creation of the model. Permutation analysis revealed the predominant role of Bio15 - precipitation seasonality $(40.6 \%)$. The influence of Bio2 - the mean diurnal temperature range (17.3\%), Bio18 - precipitation of warmest quarter (16.8\%), Bio7 - temperature range (10.8\%), and Bio8 - mean temperature of wettest quarter $(9.2 \%)$ were quite significant as well. The contribution of the remaining variables (Bio19 - precipitation of coldest quarter and Bio9 - mean temperature of driest quarter) was small and amounted, respectively, to 3.1 and $2.2 \%$.

Then the training gain was tested using an alternative jackknife test. According to this test, the most important role belongs to Bio18 (precipitation of warmest quarter) and Bio8 (mean temperature of wettest quarter). The variable Bio15 (precipitation seasonality), which occupied the first line as result of permutation, was in third place only. Bio2 (mean diurnal range) seems to be the least significant, nevertheless, the column, showing the result when removing this variable, was the shortest and much shorter than the leading Bio18 and Bio8. It means that this variable poses the largest amount of unique information. In general, both approaches have shown the leading role of temperature and precipitation. 


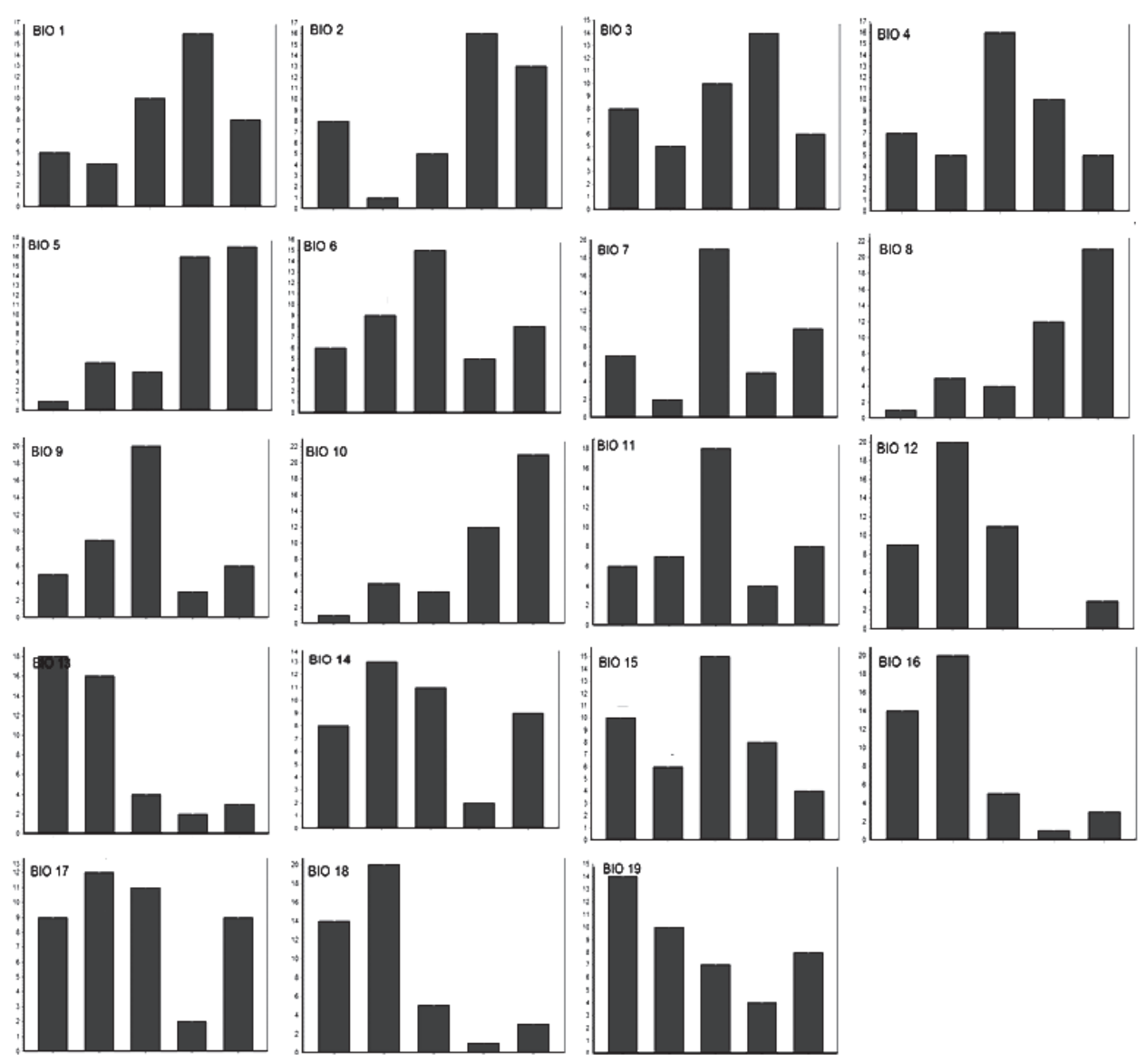

Figure 2. Variability of various climatic characteristics (Bio 1 - Bio19) of Brunnera sibirica. The names of bioclimatic characteristics are in the text. (Axis of abscissa - the factor strength, ordinate axis - the frequencies).

These results based on the current distribution of $B$. sibirica show that it prefers the quite warm and humid areas and the greatest concentration of its locations is observed in West Altai and Kuznetskiy Alatau. This area is known to be a refuge for Tertian relicts (Epova 1956; Polozhiy and Krapivkina 1985; Krapivkina 2009) and characterized with the mildest climate. At the same time, the model confirms that $B$. sibirica could grow in the west part of Russia as well.

The model for $B$. sibirica potential distribution in future environmental conditions, predicted for 2080 was constructed (Fig. 3B). The obtained model indicates that the area suitable for $B$. sibirica will not be restricted, but rather expanded to the north. While the most of Russian European part will remain poorly suited for this species, the potential expansion northward and eastward is nonetheless quite dramatic. 

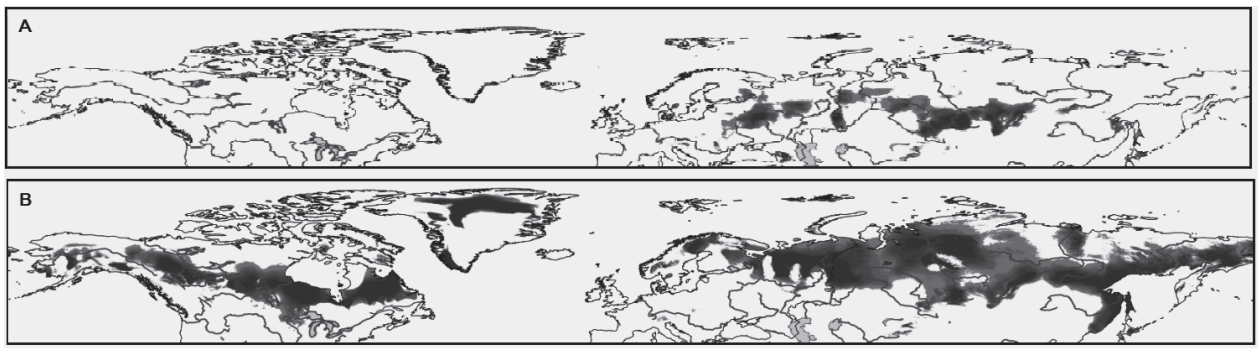

Figure 3. The model of the suitable area for Brunnera sibirica, in Eurasia in accordance with the bioclimatic variables Bio 2, 7, 8, 9, 15, 18, 19. The names of bioclimatic characteristics are in the text. A - current climate. B - climate, predicted by SCIRO for 2080 (emission scenario A2a).

\section{Conclusion}

The research has revealed that the climatic conditions in the most of Siberian territory are not suitable for the growth of B. sibirica, which confirms its relictual nature in the south of Siberia. Nevertheless, the area suitable for its growth broad in terms of the variety of temperature and precipitation conditions. Considering the climate change, by 2080, a far greater area of Siberia may become suitable leading to major expansion to the north and far east.

\section{Acknowledgements}

The authors thank the curators of ALTB, LE, MW, NS, NSK, TK for the opportunity to work with collections. The study was supported by Mendeleev fund (Tomsk State University).

\section{References}

Brown JL (2014). SDMtoolbox: a python-based GIS toolkit for landscape genetic, biogeographic and species distribution model analyses. Methods in Ecology and Evolution, 5(7): 694-700.

Brown JL. (2014) SDMtoolbox User Guide. [accessed 2020 March, 3] http://www.sdmtoolbox.org/data/sdmtoolbox/current/Detailed_Guide_Associated_w_video_SDMtoolbox.pdf

Chopic VI (1978) Rare and vulnerable plants of Ukraine. Naukova Dumka, Kiev, 216. [in Russian]

Climate date from Worldclim. [accessed 2020 March, 3] http://www.worldclim.org Dobrochaeva DN (1981) Flora of European part of the USSR. Vol. 5, 144-145. [in Russian] 
Elith J, Graham CH, Anderson RP, Dudik M, Ferrier S, Guisan A, Hijmans RJ, Huettmann F, Leathwick J, Schapire R, Soberso J, Williams S, Wisz M, Zimmerman N (2006) Novel methods improve prediction of species' distributions from occurrence data. Ecogeography 29: 129-151.

Epova NA (1956) Relics of broadleaved forests in fir taiga of Khamar-Daban. Bulletin of Biological- Geographical Scientific Research Institute at the A.A. Zhdanov Irkutsk State University 16 (1-4): 25-61. [in Russian]

ESRI (2012) ArcGIS Desktop and Spatial Analyst Extension: Release 9. Environmental Systems Research Institute, Redlands, CA. [accessed 2020 March, 11] http://www.esri.com Franklin J (2009) Mapping Species Distributions: Spatial Inference and Prediction. Cambridge University Press, Cambridge, 340.

Giovanelli GR, Haddad CFB, Alexandrino J (2007) Predicting the potential distribution of the alien invasive American bullfrog (Lithobates catesbeianus) in Brasil. Biological Invasions 10(5): 585-590.

Hijmans RJ, Guarino L, Mathur P (2012) DIVA-GIS Version 7.5 Manual. [accessed 2020 March, 3] http://diva-gis.org/docs/DIVA-GIS_manual_7.pdf

Ilyin MM (1941) Relic elements in the flora of Siberia and their possible origin. The problems of relics of the flora of the USSR 2: 26-31. [in Russian]

Kleopov YD (1941) Main features of development of the flora of broadleaved forests of the European part of the USSR. Materials of the history of flora and vegetation of the USSR. Moscow-Leningrad, 183-256. [in Russian]

Krapivkina ED (2009) Nemoral relics in the flora of chern taiga of Gornaya Shoria. SO RAN Publishing House, Novosibirsk, 229. [in Russian]

Maevskiy PF (2006) Flora of the middle part of European part of Russia. 10th edition. KMK Scientific Press, Moscow, 600. [in Russian]

Meffe GK, Carroll CR and contributors (1994) Principles of Conservation Biology. Sinauer Associates, Inc., Sunderland, Massachusetts, 600.

Nikiforova OD (1997) Brunnera Steven. Flora of Siberia 11: 116. [in Russian]

Nix HA (1986) A Biogeographic Analysis of Australian Elapid Snakes. Australian Flora and Fauna Series Number 7: Atlas of Elapid Snakes of Australia. Australian Government Publishing Service, Canberra, 4-15.

Phillips SJ, Anderson RP, Schapire RE (2006) Maximum entropy modeling of species geographic distributions. Ecological Modelling 190: 231-259.

Phillips SJ, AT\&T Research. A brief tutorial on MaxEnt. [accessed 2020 March, 2] http://users.clas.ufl.edu/mbinford/GEO5159_GIS_Environmental/References_for_links/MaxEnt\%20Tutorial.doc

Phillips SJ, Dudic M (2008) Modeling of species distribution with Maxent: new extentions and a comprehensive evaluation. Ecography 31: 161-175.

Polozhiy AV, Krapivkina ED (1985) Relics of tertiary broadleaved forests in the Siberian flora. Publishing House of the Tomsk State University, Tomsk, 157. [in Russian]

Popov MG (1958) Flora of Baikal Siberia and its origin. Selected Works. Publishing House of Turkmen SSR, Ashkhabad, 473-488. [in Russian] 
Red Data Book of the Krasnoyarsk territory (2012) The Rare and Endangered Species of Animals. 3th edition, revised and added. Siberian Federal University Publishing House, Krasnoyarsk, 205. [in Russian]

Red Data Book of Altai Republic (1996) Rare and Vulnerable Plants Species. Central Siberian Botanical Garden of the Siberian Branch of the RAS, Novosibirsk, 130. [in Russian]

Red Data Book of Altaiskiy krai (2006) Rare and Vulnerable Plants Species. IPP Altai, Barnaul, 262. [in Russian]

Red Data Book of the Kemerovo Region (2012) Volume I. Rare and Vulnerable Species of Plants and Fungi. 2nd edition, revised and added. Asia Print, Kemerovo, 208. [in Russian]

Red Data Book of Novosibirsk Province: Plants (1998) Nauka, Novosibirsk, 144. [in Russian]

Red Data Book of Tyva Republic: Plants (1999) Publishing House of the Siberian Branch of RAS, Novosibirsk, 150. [in Russian]

Red Data Book of Tomsk Oblast (2013) Rare and Vulnerable Species of Plants and Fungi. 2nd edition, revised and added. Pechatnaya Manufactura, Tomsk, 504. [in Russian]

Scheldeman X, van Zonneveld M (2010) Training manual on spatial analysis of plant diversity and distribution. Biodiversity International, Rome, 180.

Ward DF (2007) Modelling the potential geographic distribution of invasive ant in New Zeland. Biological Invasions 9: 723-735.

Wintergoller BA, Rubanik VG, Nilov VN (1983) Rare and vulnerable plants species of natural flora of the USSR, cultivated in botanical gardens and other introduction centers. Nauka, Moscow, 304. 